\title{
A Performance Evaluation Model for Global Macro Funds
}

\author{
Adam Zaremba \\ Poznań University of Economics, Poland
}

\begin{abstract}
The paper concentrates on value and size effects in country portfolios. It contributes to academic literature threefold. First, I provide fresh evidence that the value and size effects may be useful in explaining the cross-sectional variation in country returns. The computations are based on a broad sample of 66 countries in years 2000-2013. Second, I document that the country-level value and size effects are indifferent to currency conversions. Finally, I introduce an alternative macro-level Fama-French model, which, contrary to its prototype, employs country-based factors. I show that applying this modification makes the model more successful in evaluation of funds with global investment mandate than the standard CAPM and FF models.
\end{abstract}

Keywords: Fama-French model, value effect, size effect, country returns, cross section of returns, hedge funds, investment performance evaluation.

JEL CODE: G21, G32, C61 G11, M 59

C 2013 Published by SSBFNET

\section{Introduction}

Hedge funds' performance evaluation is not an easy task. This sentence is particularly true when it comes to global macro funds. Multiple markets and asset classes in a portfolio, lack of any predefined benchmark, time-varying exposures and skewed distributions of returns pose a serious problem. As a result, performance measures based on traditional models may be not fully appropriate.

The standard performance measures, which are often based on CAPM or Fama-French (FF) pricing model, do not seems to work very well. On the one hand, the CAPM model obviously does not take into account various pricing anomalies, like size or value effects. On the other hand, the FF model's factors may be not applicable and difficult to replicate in the case of global macro hedge funds, which may invest in international markets and have various exotic exposures. In this manuscript I try to propose an alpha measurement method which can at least partially fix these shortcomings.

The paper is composed of three main parts. Firstly, I review the Fama-French model and describe how it could be converted into global dimension. Secondly, I describe the data source and research methods employed. Eventually, I present the research results. On the one hand, I analyze the presence of value and size effects on the macro level and check whether the premiums are indifferent to the changes of basic currency. I perform the computations on the probably broadest sample examined so far, which includes data on 66 country portfolios from years 2000-2013. 
Additionally, I use two distinct types of indices. On the other hand, I show how the macro-level factors may be used to improve the performance assessment of the funds with global investment policy, like for instance global macro funds.

This research aims to broadens the existing academic knowledge in three ways. First, I confirm the presence of the value and size premiums at the country level. Second, I document that the country-level premiums are robust to the changes of fundamental currency or country index. Thirdly, I propose a new macro-level Fama-French model, which may be applied to global investment funds' performance assessment.

\section{Theoretical basis}

The Capital Asset Pricing Model (Sharpe 1964, 1966, Lintner 1965, Mossin 1966) was once a widely accepted model for funds' performance assessment. The alternative factor models, which emerged in the last 20-years, were an answer to numerous market anomalies observed. The Fama-French three-factor model (Fama \& French 1993) can serve as an example. Besides the market risk factor, it additionally involves two additional factors which generally refers to the size and value anomalies.

The size effect was probably firstly documented by Banz (1981). Banz, basing on NYSE stocks in years $1936-1975$, found that the smallest 20 per cent of firms earn an annual return that is 5 per cent higher than the return on other firms. In the other words, he showed that stocks with lower capitalization (small stocks) tend to have higher average returns. Reinganum (1981), Cook and Roseff (1982) Blume and Stambaugh (1983), Brown et al. (1983) confirmed the evidence of the size effect by using a broader sample and decile portfolios. The size effect was also detected in several international markets by a variety of researchers (Herrera \& Lockwood 1994, Heston at al. 1999, Rouwenhorst 1999, Horowitz et al. 2000a, Fama and French 2008, Michou et al. 2010). However, Fama and French (2012) did not find the size premium in any of four global regions after examining returns over a 20-year horizon starting in 1990. Dimson et al. (2011) observed that higher returns of smaller companies did not exist for long periods of time.

The value effect is tendency of value stocks (stocks with low prices relative to their fundamentals) to outperform growth stocks (stocks with high prices relative to their fundamentals). The research in this field can be dated back to Basu (1975). Formal statistical evidence of the value effect were presented by Stattman (1980) and Rosenberg (1985). They used the book to market ratio as a value indicator. Davis et al. (1994) confirmed the value effect in US stock markets. Chan et al. (1991) and Capaul et al. (1993) confirmed the value effect, but in outside the US markets. The value effect was observed in stocks returns, Fama and French (1998, 2011), Rouwenhorst (1999), Lam (2002), Ghargohori (2009), Chui, Titman and Wei (2010) and Asness, Moskowitz, and Pedersen (2013).

The size and value factors are traditionally derived from individual stocks and used to explain cross-sectional variation in their returns. But can we also observe some similarities at the macro level? Can the country stock market returns be forecasted basing on cross-country value and size factors? The papers examining this issues seems to say yes, however the evidence is rather modest. There has been few paper so far which try to extend the value and size effects to country 
indices. The examples are manuscripts by Asness et al. (1997), who concentrate on documents both size and value anomalies, and Bhojraj and Swaminathan (2006), who confirm the value effect. Garff (2013) analyzes a samples of 18 to 41 countries and find the evidence country-level value effect, however the research lacks formal statistical inferences. Ansess et al. (2012) on the contrary also find convincing statistical evidence, but includes only from 8 to 18 countries in the sample.

If macro-level value and size factors really exist, they could be helpful in intenrational funds' performance assessment. It is especially true for global macro hedge funds, which take both long and short position, and thus their investment results are particularly difficult to assessa. The quasi-Fama-French factor model with factors based on country portfolios could be particularly useful because of three reasons. First, it would much better reflect the global investment policy of global macro funds. Second, it could allow for simultaneous long and short positions in various market segments. Third, the factors could be more easily replicated than in case of broadly diversified portfolios of single stocks. Most equity indices, especially the local ones, can be cheaply accessed through liquid future contracts, which is not always true when it comes to illiquid small-cap or value stocks.

\section{Research methods and data sources}

I investigate the issue of returns to value and size factors as an explanation for variation in cross-sectional country returns using data from 66 different countriesb and two types of indices. First, I use the MSCI indices, which guarantee identical computational methodology along all the markets. Unfortunately, MSCI indices are not always easily replicable, what may seem not very practical from an investor perspective. Therefore, I perform another parallel research based on local indicesc, which in each case can be replicated at low cost with a passive ETF or a future contract. Therefore, this type of indices seems to be more appropriate for performance measurement. In other words, I perform actually two similar analyses based on slightly different basic data. In case there is no data for one type of index in a given country, I use the index from the other group. The data on prices and fundamental factors come from Bloomberg.

\footnotetext{
${ }^{a}$ Some reviews of hedge fund performance measurement methods can be found for example in publications of Lhabitant (2004, 2007).

${ }^{b}$ Argentina, Australia, Austria, Bahrain, Belgium, Brazil, Bulgaria, Canada, Chile, China, Colombia, Cyprus, Czech Republic, Denmark, Egypt, Estonia, Finland, France, Germany, Great Britain, Greece, Hong Kong, Hungary, Iceland, India, Indonesia, Ireland, Italy, Japan, Jordan, Kuwait, Latvia, Lebanon, Lithuania, Luxemburg, Malaysia, Mexico, Morocco, Netherlands, New Zealand, Norway, Oman, Pakistan, Peru, Philippines, Poland, Portugal, Qatar, Romania, Russia, Saudi Arabia, Singapore, Slovenia, South Africa, South Korea, Spain, Sweden, Switzerland, Taiwan, Thailand, Turkey, Ukraine, Un. Arab Emirates, USA, Venezuela, Vietnam.

${ }^{c}$ OMX Riga OMXR, BLOM Stock Index, OMX Vilnius OMXV, Luxembourg LuxX Index, FTSE Bursa Malaysia KLCI, Mexixp IPC Index, MADEX Free Float Index, AEX-Index, NZX ALL Index, OBX Price Index, MSM30 Index, Karachi 100 Index, Peru Lima General Index, PSEi - Philipine SE IDX, WIG 20, PSI 20 INDEX, QE Index, Bucharest BET Index, MICEX Index, TADAWUL ALL SHARE Index, Straits Times Index STI, Slovenian Blue Chip Idx, FTSE/JSE Africa ALL SHR, Kospi Index, IBEX 35 Index, OMX Stockholm 30 Index, Swiss Market Index, Taiwan TAIEX Index, Stock Exchange of Thai Index, BIST National 100 Index, PFTS Index, ADX General Index, S\&P 500 Index, Venezuela STOCK MKT, Ho Chi Minh Stock Index.
} 
First, I analyze the factor returns in the international markets. I sort all the markets in a given time on two factors: value and size. The value factor $(\mathrm{V})$ is the book-to-market value ratio (BV/MV) of the country portfolio computed according to the specific index weighing methodology. The size factor (S) is the market capitalization of all companies in a country portfolio. I include a market into the sample if at a given point of time I have both data pieces indicated above. Therefore, the number of stocks in the sample grows along with the development of worldwide capital markets: from 47 in the beginning of the research period to 66 in the end in case of the MSCI indices, and from 24 to 66 in case of local indices. I use complete time-series data (encompassing all the data described above) from the timespan 05/31/2000-11/29/2013. I do not analyze the earlier period because I am afraid that too small number of various countries in the sample could disturb the results. I perform all the computations on monthly data.

Knowing the V and S characteristics, I construct three separate portfolios for each factor including $30 \%$ of markets with the lowest factor, $30 \%$ of markets with the highest factor and the remaining $40 \%$ of the mid-markets. I use an equal weighting scheme, as I assume that the markets as a whole are liquid enough to validate this approach. Along with the factor portfolios, I calculate also returns on a market portfolio. As the proxy for the market portfolio, I use capitalization weighted average of all the markets included in the research. I perform all the computation in three distinct currency schemes: US dollars (USD), euros (EUR) and Japanese yens (JPY). In other words, I convert all the data to into USD, EUR and JPY, and deliver three versions of results. It is important to note that the choice of basic currency impacts the data in three important ways. First, the currency fluctuations influence the variation in returns. Second, the size of the market measured with capitalization may change, influencing the construction of size-sorted portfolios. Finally, the composition of the market portfolio is can differ slightly in case of each currency convention.

Next, I build fully collateralized market-neutral (MN) long/short portfolios mimicking behavior of certain factors. The collateralized MN portfolios' construction bases on existing theoretical and empirical evidence in the field, so as to make them positively exposed to factor-related premiums. In other words, the portfolios are always long in the $30 \%$ of markets, which yield the highest risk-adjusted returns, short in the 30\% of markets which yield the lowest risk-adjusted returns and $100 \%$ long in the risk-free asset. As the result, I create two distinct portfolios: market neutral long/short value mimicking portfolio ("V MN"), which is $100 \%$ long in the $30 \%$ highest BV/MV country portfolios, $100 \%$ short in the $30 \%$ lowest BV/MV country portfolios and $100 \%$ long in the risk free asset; and market neutral long/short size mimicking portfolio ("S MN"), which is $100 \%$ long in the $30 \%$ smallest country portfolios and $100 \%$ short in the $30 \%$ biggest country portfolios (in terms of capitalization) and $100 \%$ long in the risk free asset. Again, similarly as in the previous case, the portfolios are equal weighted.

Finally, the performance of long/short MN portfolios is tested against four different models: zero model, market model, CAPM and Fama-French three factor modeld. Here, I base my computations on logreturns. The first one

\footnotetext{
${ }^{d}$ A more detailed review and description of expected return models can be found for example in Cambell, Lo \& MacKinlay (1997) and Cochrane (2005).
} 
basically assumes that the expected return on security is zero, so I test whether the actual returns are statistically different form zero. The second model is the classical market model, as introduced by Fama et al. (1969):

$$
\begin{aligned}
& R_{i t}=\alpha_{i}+\beta_{i} R_{m t}+\varepsilon_{i t}, \\
& E\left(\varepsilon_{i t}\right)=0, \operatorname{var}\left(\varepsilon_{i t}\right)=\sigma_{\varepsilon}^{2}
\end{aligned}
$$

where Rit and Rmt are the period-t returns on security and the market portfolio, eit is the zero mean disturbance term and $\alpha \mathrm{i}, \beta \mathrm{i}$ and $\sigma \varepsilon^{\wedge} 2$ are the parameters of the market model. Identically as in the earlier calculations, I use the valueweighted average of all markets.

The other model I employ is the Capital Asset Pricing Model (Sharpe 1964, 1966, Lintner 1965, Mossin 1966). The long/short portfolios' excess returns are regressed on market portfolio's excess returns, accordingly to the CAPM equation:

$$
R_{i t}-R_{f t}=\alpha_{i}+\beta_{i}\left(R_{m t}-R_{f t}\right)+\varepsilon_{i t},
$$

where Rit, Rmt and Rft are annual long/short portfolio, market portfolio and risk-free returns, and $\alpha \mathrm{i}$ and $\beta \mathrm{i}$ are regression parameters. I used 1-month BBA Libor USD, Euribor and Tibor to represent the risk-free rate in the USD, EUR and JPY approaches. The ai intercept measures the average annual abnormal return (so called Jensen-alpha). Finally, the last model is the Fama-French three factor model (Fama \& French 1992, 1993):

$$
\mathrm{R}_{\mathrm{it}}=\alpha+\mathrm{R}_{\mathrm{f}}+\beta_{\mathrm{rm}} \cdot\left(\mathrm{R}_{\mathrm{mt}}-\mathrm{R}_{\mathrm{f}}\right)+\beta_{\mathrm{SMB}} \cdot \mathrm{SMB}+\beta_{\mathrm{HML}} \cdot \mathrm{HML}+\varepsilon_{i t},
$$

where $\beta_{\mathrm{rm}}, \beta_{\mathrm{SMB}}, \beta_{\mathrm{HML}}$, and $\alpha$ ere the estimated parameters of the model. $\beta_{\mathrm{rm}}$ is analogical to the CAPM beta, but it is not equal to it. The $\beta_{\mathrm{SMB}}, \beta_{\mathrm{HML}}$ are exposed to SMB HML risk factors, which denote returns from zero-cost arbitrage portfolios, which are long small-caps and short large-caps (SMB), and long high BV/MV stocks and short low BV/MV stocks (HML). I use the factors computed by Kenneth French and available at his websitee.

In all the models, my zero hypothesis is that the alpha intercept is not statistically different from zero, and the alternative hypothesis states that it actually differs from zero. I find the equation parameters using OLS and test them in a parametric way.

Finally, I use the computed factor portfolios to build an alternative, macro-level Fama-French three-factor model (further on: macro-FF model). The general construction is identical to the traditional FF model (1993), however I define the HML and SMB factors in a different way. Further on, I will denote them macro-value factor (HMLM) and macro-size factor (SMBM), in order indicate that those are the macro-level HML and SML factors. As their proxy, I use the non-collateralized V MN and S MN portfolios, computed identically as before, but without adding the risk-free

\footnotetext{
${ }^{e}$ http://mba.tuck.dartmouth.edu/pages/faculty/ken.french/data_library.html
} 
rate. In other words, HMLM is a zero-cost portfolio which is $100 \%$ long in the $30 \%$ highest BV/MV country portfolios and $100 \%$ short in the $30 \%$ lowest BV/MV country portfolios, and SMBM is a zero-cost portfolio, which is $100 \%$ long in the $30 \%$ smallest country portfolios and $100 \%$ short in the $30 \%$ biggest country portfolios (in terms of capitalization). Again, the portfolios are equal weightedf.

In order to test the performance of the model, I apply it to assess the investment results of global macro hedge funds. As their proxy, I use three distinct broadly recognized global macro hedge fund indices: Credit Suisse Global Macro Index (SCGM), Barclay Global Macro Hedge Fund Index SCGM (BGMHF) and Eurekahedge Global Macro Fund of Funds Index SCGM (EGMFF). It's worth noticing, that the last index can be probably most easily replicated, as it is based on funds-of-funds. In the end, I compare the applicability of my macro-level FF model with the traditional CAPM and FF model.

\section{Results and interpretation}

The return characteristics of various factor sorted portfolios are exhibited in the table 1 . Both factors - value and size seem to be important for portfolio formation. First, the markets with high BV/MV ratio deliver on average higher returns than low BV/MV returns. This observation concerning the country portfolios' level is consistent with the previous research referring to the single companies' level. Second, the small markets (in terms of capitalization) deliver higher returns than large markets. Additionally, all the described observations are robust to the choice of currency or representative index.

Table 1. Performance of factor sorted portfolios.

\begin{tabular}{lccccccccc}
\hline & \multicolumn{3}{c}{ Returns } & \multicolumn{3}{c}{ Volatility } & & \multicolumn{2}{c}{ Beta } \\
mid & high \\
\hline & low & mid & high & low & mid & low & MSCI Indices \\
V USD & $0,21 \%$ & $0,58 \%$ & $0,66 \%$ & $5,81 \%$ & $5,76 \%$ & $6,57 \%$ & 1,07 & 1,06 & 1,17 \\
V EUR & $-0,02 \%$ & $0,35 \%$ & $0,43 \%$ & $5,06 \%$ & $4,72 \%$ & $5,61 \%$ & 1,04 & 0,95 & 1,07 \\
V JPY & $0,18 \%$ & $0,55 \%$ & $0,63 \%$ & $6,60 \%$ & $6,55 \%$ & $7,36 \%$ & 1,05 & 1,04 & 1,14 \\
S USD & $0,75 \%$ & $0,50 \%$ & $0,22 \%$ & $5,76 \%$ & $6,31 \%$ & $6,02 \%$ & 0,94 & 1,18 & 1,16 \\
S EUR & $0,52 \%$ & $0,26 \%$ & $-0,01 \%$ & $4,84 \%$ & $5,41 \%$ & $5,06 \%$ & 0,82 & 1,11 & 1,09 \\
S JPY & $0,72 \%$ & $0,46 \%$ & $0,19 \%$ & $6,58 \%$ & $7,05 \%$ & $6,83 \%$ & 0,95 & 1,13 & 1,12 \\
\hline & & & & Local indices & & & \\
V USD & $0,34 \%$ & $0,59 \%$ & $0,69 \%$ & $5,61 \%$ & $5,75 \%$ & $6,60 \%$ & 1,02 & 1,06 & 1,17 \\
V EUR & $0,12 \%$ & $0,36 \%$ & $0,45 \%$ & $4,80 \%$ & $4,75 \%$ & $5,58 \%$ & 0,96 & 0,96 & 1,05 \\
V JPY & $0,31 \%$ & $0,57 \%$ & $0,65 \%$ & $6,42 \%$ & $6,59 \%$ & $7,31 \%$ & 1,01 & 1,05 & 1,12 \\
S USD & $0,79 \%$ & $0,60 \%$ & $0,22 \%$ & $5,88 \%$ & $6,16 \%$ & $5,97 \%$ & 0,97 & 1,12 & 1,14 \\
S EUR & $0,56 \%$ & $0,37 \%$ & $-0,01 \%$ & $4,99 \%$ & $5,19 \%$ & $5,00 \%$ & 0,87 & 1,03 & 1,06 \\
S JPY & $0,76 \%$ & $0,57 \%$ & $0,19 \%$ & $6,65 \%$ & $6,95 \%$ & $6,77 \%$ & 0,97 & 1,09 & 1,10 \\
\hline
\end{tabular}

Portfolios are sorted according to BV/MV ("V") and capitalization ("S"). USD, EUR and JPY denote the currency approach. "Return" is an average monthly logreturn, "volatility" is a standard deviation of monthly logreturns, "beta" is regression coefficient calculated against a market portfolio. The market portfolio is computed as a capitalization weighted average of the country portfolio returns. The

\footnotetext{
${ }^{f}$ Please note, that the details of exact factor computation method (weighting scheme, breakpoints for size portfolios) are slightly different than in the classical FF model.
} 
data source is Bloomberg and the computations are based on listings from 66 countries during a period 05/31/2000-11/29/2013. The MSCI and local indices are used.

The table 2 reveals information about the performance of collateralized factor mimicking market-neutral portfolios and their statistical significance. The value and size factors yielded positive returns, which were significantly different from zero, no matter what currency or type of index I examine.

The positive returns remain statistically significant after adjusting for risk in the CAPM approach. The Fama-French model indicates, that some of the variation in returns of the cross-country returns may be explained by the size and value factors. For example, the HML and SMB factors explain almost fully the global cross-country value factor. What is interesting, this relationship works in all the currency approaches. Additionally - what may seem quite surprising - the size factor is partly explained by HML. Finally, no factor returns remain statistically significant after applying FF three-factor model.

The table 3 contains information on the performance assessment of global macro funds with CAPM, FF and macro-FF models.

The table provides a few interesting insights. First, the macro-value and macro-size factors are statistically more significant than the standard HML and SMB factors. Particularly, the SMBM factor appears to be quite exceptional, when one looks at the t-stats. These observations are generally true for all the indices and ways of factor computation (local or MSCI). Second, the macro-F F model does much better job in explaining variation in returns than CAPM or FF. The $\mathrm{R}^{2}$ indicators are sometimes twice or thrice higher. Third, The F-stats or all the macro-FF equations are higher than in case of FF models. Finally, it should be noted, that the macro-FF model seems to work better with MSCI indices than with local equity indices. 
Zaremba /International Journal of Finance \& Banking Studies Vol 3, No 1, 2014 ISSN: 2147-4486

Table 2. Performance of market-neutral factor-mimicking portfolios.

\begin{tabular}{|c|c|c|c|c|c|c|c|c|c|c|}
\hline & \multicolumn{2}{|c|}{ Zero model } & \multicolumn{2}{|c|}{ Market model } & \multicolumn{2}{|c|}{ CAPM } & \multicolumn{4}{|c|}{ Fama-French three factor model } \\
\hline & Return & Volatility & $\beta$ & $\alpha$ & $\beta$ & $\alpha$ & HML & SMB & Rm-Rf & $\alpha$ \\
\hline \multicolumn{11}{|c|}{ MSCI indices } \\
\hline \multirow[t]{2}{*}{ V USD } & $0,64 \%$ & $2,93 \%$ & 0,09 & $0,62 \%$ & 0,09 & $0,45 \%$ & 0,22 & 0,21 & 0,01 & $0,27 \%$ \\
\hline & $(2,77)$ & & $(1,99)$ & $(2,72)$ & $(2,05)$ & $(1,99)$ & $(3,46)$ & $(2,44)$ & $(0,24)$ & $(1,25)$ \\
\hline \multirow[t]{2}{*}{ V EUR } & $0,62 \%$ & $2,96 \%$ & 0,03 & $0,63 \%$ & 0,03 & $0,44 \%$ & 0,24 & 0,24 & $-0,06$ & $0,21 \%$ \\
\hline & $(2,69)$ & & $(0,52)$ & $(2,69)$ & $(0,66)$ & $(1,89)$ & $(3,85)$ & $(2,87)$ & $(-1,18)$ & $(0,95)$ \\
\hline V JPY & $0,48 \%$ & $2,90 \%$ & 0,08 & $0,47 \%$ & 0,08 & $0,45 \%$ & 0,21 & 0,20 & 0,02 & $0,28 \%$ \\
\hline \multirow[t]{2}{*}{ S USD } & $0,64 \%$ & $3,36 \%$ & $-0,23$ & $0,68 \%$ & $-0,23$ & $0,45 \%$ & 0,17 & 0,10 & $-0,28$ & $0,35 \%$ \\
\hline & $(2,43)$ & & $(-4,74)$ & $(2,75)$ & $(-4,68)$ & $(1,83)$ & $(2,35)$ & $(1,03)$ & $(-5,27)$ & $(1,39)$ \\
\hline \multirow[t]{2}{*}{ S EUR } & $0,66 \%$ & $3,31 \%$ & $-0,27$ & $0,64 \%$ & $-0,26$ & $0,40 \%$ & 0,15 & 0,10 & $-0,31$ & $0,28 \%$ \\
\hline & $(2,53)$ & & $(-4,97)$ & $(2,65)$ & $(-4,80)$ & $(1,65)$ & $(2,25)$ & $(1,08)$ & $(-5,34)$ & $(1,15)$ \\
\hline \multirow[t]{2}{*}{ S JPY } & $0,48 \%$ & $3,33 \%$ & $-0,17$ & $0,50 \%$ & $-0,17$ & $0,48 \%$ & 0,15 & 0,07 & $-0,20$ & $0,39 \%$ \\
\hline & $(1,82)$ & & $(-3,99)$ & $(2,00)$ & $(-3,97)$ & $(1,90)$ & $(2,06)$ & $(0,70)$ & $(-4,41)$ & $(1,56)$ \\
\hline \multicolumn{11}{|c|}{ Local indices } \\
\hline V USD & $0,55 \%$ & $2,66 \%$ & 0,14 & $0,53 \%$ & 0,14 & $0,37 \%$ & 0,18 & 0,11 & 0,09 & $0,25 \%$ \\
\hline \multirow[t]{2}{*}{ V EUR } & $0,54 \%$ & $2,69 \%$ & 0,08 & $0,54 \%$ & 0,08 & $0,36 \%$ & 0,22 & 0,15 & 0,02 & $0,20 \%$ \\
\hline & $(2,54)$ & & $(1,71)$ & $(2,57)$ & $(1,85)$ & $(1,73)$ & $(3,79)$ & $(1,90)$ & $(0,39)$ & $(0,97)$ \\
\hline \multirow[t]{2}{*}{ V JPY } & $0,39 \%$ & $2,64 \%$ & 0,10 & $0,37 \%$ & 0,10 & $0,35 \%$ & 0,19 & 0,12 & 0,06 & $0,23 \%$ \\
\hline & $(1,88)$ & & $(3,05)$ & $(1,84)$ & $(3,06)$ & $(1,75)$ & $(3,44)$ & $(1,57)$ & $(1,58)$ & $(1,18)$ \\
\hline \multirow[t]{2}{*}{ S USD } & $0,70 \%$ & $3,13 \%$ & $-0,18$ & $0,73 \%$ & $-0,17$ & $0,51 \%$ & 0,20 & 0,06 & $-0,22$ & $0,41 \%$ \\
\hline & $(2,84)$ & & $(-3,89)$ & $(3,11)$ & $(-3,84)$ & $(2,19)$ & $(3,08)$ & $(0,61)$ & $(-4,57)$ & $(1,77)$ \\
\hline \multirow[t]{2}{*}{ S EUR } & $0,72 \%$ & $3,06 \%$ & $-0,20$ & $0,71 \%$ & $-0,19$ & $0,48 \%$ & 0,19 & 0,05 & $-0,23$ & $0,38 \%$ \\
\hline & $(2,98)$ & & $(-3,99)$ & $(3,09)$ & $(-3,80)$ & $(2,08)$ & $(2,90)$ & $(0,58)$ & $(-4,39)$ & $(1,63)$ \\
\hline \multirow[t]{2}{*}{ S JPY } & $0,53 \%$ & $3,12 \%$ & $-0,13$ & $0,56 \%$ & $-0,13$ & $0,53 \%$ & 0,19 & 0,03 & $-0,17$ & $0,45 \%$ \\
\hline & $(2,18)$ & & $(-3,42)$ & $(2,34)$ & $(-3,40)$ & $(2,24)$ & $(2,84)$ & $(0,35)$ & $(-3,97)$ & $(1,91)$ \\
\hline
\end{tabular}

Portfolios are created based on $B V / M V$ (" $V$ ") and stock market total capitalization ("S"). USD, EUR and JPY denote the currency approach. "Return" is the average annual geometric rate of return and "volatility" is an annual standard deviation of logreturns. HML, SMB, Rm-Rf, $\alpha$ and $\beta$ are model parameters computed in each case according to the model' specification. I use logreturns in all computations. Data on HML and SML factor comes from Kenneth's R. French website. The market portfolio is computed as the capitalization weighted average of country portfolio returns. As the proxy for the money market returns, I use I-month bids for BBA Libor USD, Euribor and Tibor for USD, EUR and JPY approaches. Numbers in brackets below denote the statistical significance (t-stat). The data source is Bloomberg and the calculations are based on listings from 66 countries during a period 05/31/2000-11/29/2013. The MSCI and local indices are used. The modes are estimated using OLS and tested in a parametric way. 
Table 3. Global macro funds' performance assessment with CAPM, FF and macro-FF models.

\begin{tabular}{|c|c|c|c|c|c|c|c|c|c|c|c|c|c|c|c|c|}
\hline & \multicolumn{4}{|c|}{ CAPM } & \multicolumn{6}{|c|}{ FF model } & \multicolumn{6}{|c|}{ Macro FF model } \\
\hline & $\beta$ & $\alpha$ & $\mathrm{R} 2$ & F-stat & HML & SMB & MP & $\alpha$ & $\mathrm{R} 2$ & F-stat & HMLM & SMBM & MP & $\alpha$ & $\mathrm{R} 2$ & F-stat \\
\hline \multicolumn{17}{|c|}{ MSCI indices } \\
\hline \multirow[t]{2}{*}{ SCGM } & 0,09 & 0,01 & $9,0 \%$ & 15,8 & 0,00 & $-0,03$ & 0,10 & 0,01 & $9,3 \%$ & 5,4 & $-0,07$ & 0,16 & 0,12 & 0,01 & $20,6 \%$ & 13,6 \\
\hline & $(3,97)$ & $(6,18)$ & & & $(0,12)$ & $(0,75)$ & $(3,88)$ & $(6,17)$ & & & $(1,98)$ & $(4,78)$ & $(5,55)$ & $(5,59)$ & & \\
\hline \multirow[t]{2}{*}{ BGMHF } & 0,16 & 0,00 & $30,0 \%$ & 68,6 & $-0,04$ & 0,03 & 0,16 & 0,00 & $31,3 \%$ & 24,0 & $-0,05$ & 0,11 & 0,18 & 0,00 & $34,9 \%$ & 28,2 \\
\hline & $(8,28)$ & $(3,30)$ & & & $(1,59)$ & $(0,81)$ & $(7,70)$ & $(3,27)$ & & & $(1,44)$ & $(3,42)$ & $(9,17)$ & $(2,76)$ & & \\
\hline \multirow[t]{2}{*}{ EGMFF } & 0,06 & 0,00 & $5,6 \%$ & 9,5 & $-0,03$ & 0,01 & 0,07 & 0,00 & $6,3 \%$ & 3,5 & $-0,05$ & 0,14 & 0,09 & 0,00 & $16,4 \%$ & 10,4 \\
\hline & $(3,08)$ & $(3,00)$ & & & $(1,04)$ & $(0,30)$ & $(2,96)$ & $(2,99)$ & & & $(1,54)$ & $(4,47)$ & $(4,52)$ & $(2,28)$ & & \\
\hline \multicolumn{17}{|c|}{ Local indices } \\
\hline \multirow[t]{2}{*}{ SCGM } & 0,09 & 0,01 & $9,0 \%$ & 15,8 & 0,00 & $-0,03$ & 0,10 & 0,01 & $9,3 \%$ & 5,4 & $-0,06$ & 0,11 & 0,11 & 0,01 & $12,9 \%$ & 7,8 \\
\hline & $(3,97)$ & $(6,18)$ & & & $(0,12)$ & $(0,75)$ & $(3,88)$ & $(6,17)$ & & & $(1,20)$ & $(2,67)$ & $(4,66)$ & $(5,76)$ & & \\
\hline \multirow[t]{2}{*}{ BGMHF } & 0,16 & 0,00 & $30,0 \%$ & 68,6 & $-0,04$ & 0,03 & 0,16 & 0,00 & $31,3 \%$ & 24,0 & $-0,05$ & 0,07 & 0,18 & 0,00 & $31,5 \%$ & 24,2 \\
\hline & $(8,28)$ & $(3,30)$ & & & $(1,59)$ & $(0,81)$ & $(7,70)$ & $(3,27)$ & & & $(1,17)$ & $(1,82)$ & $(8,23)$ & $(3,05)$ & & \\
\hline \multirow[t]{2}{*}{ EGMFF } & 0,06 & 0,00 & $5,6 \%$ & 9,5 & $-0,03$ & 0,01 & 0,07 & 0,00 & $6,3 \%$ & 3,5 & $-0,05$ & 0,10 & 0,08 & 0,00 & $9,5 \%$ & 5,5 \\
\hline & $(3,08)$ & $(3,00)$ & & & $(1,04)$ & $(0,30)$ & $(2,96)$ & $(2,99)$ & & & $(1,23)$ & $(2,62)$ & $(3,84)$ & $(2,62)$ & & \\
\hline
\end{tabular}

HML, SMB, HMLM, SMBM, Rm-Rf, $\alpha$ and $\beta$ are model parameters computed in each case according to the model' specification. I use logreturns in all computations. Data on HML and SML factors comes from Kenneth's R. French website, while data on HMLM and SMBM factors come from own computations. The market portfolio is computed as the capitalization weighted average of country portfolio returns. As the proxy for the money market returns, I use 1-month bids for BBA Libor USD. Numbers in brackets below denote the statistical significance (t-stat). The data source is Bloomberg and the calculations are based on listings from 66 countries during a period 05/31/2000-11/29/2013. The MSCI and local indices are used. The modes are estimated using OLS and tested in a parametric way. 


\section{Conclusions and Areas for Further Research}

The research presented in this paper provides a few interesting insights. Basing on a broad sample of 66 distinct countries, I document the value and size effects are present at the macro level. The computations show, that the low book-to-market countries perform better then high book-to-market ratio countries. Additionally, small markets yield on average better risk-adjusted rates of return than large markets. The macro-value and macro-size factors allow for construction of market-neutral portfolios, which deliver decent positive riski-adjusted returns. The observations above are robust to changes in the fundamental currency and work either for US dollars, euros or Japanese yens.

The alternative macro-FF model may be build based on observations of country-level size and value factors, computed as zero-cost market neutral portfolios. The model can be applied to evaluate the performance of funds with global investment policy, like for example global macro class of hedge funds ( Table 3). It appears to work better than the standard three-factor Fama-French model.

The further research should focus primarily on two areas. First, it would be interesting to convert other pricing models to the macro level as well and verify how useful they are. The Carhart model, employing the macro-momentum factor, could just serve as an example. It would be useful for instance for managed futures funds' performance assessment. Second, an effort should be made to find the sources of macro-size and macro-value factors. In other words, future research in this field should try to find an answer why these factors actually work.

\section{References}

Asness, C.S., Moskowitz T.J. \& Pedersen L. H. (2013). Value and momentum everywhere, The Journal of Finance, 68(3), 929-985.

Basu S. (1975). The Information Content of Price-Earnings Ratios, Financial Management, 4(2), 53-64.

Blume M. \& Stambaugh R. (1983). Biases in computed returns: an application to the size effect, Journal of Financial Economics, 12, 387- 404.

Brown P, Keim D.B, Kleidon A.W \& Marsh T.A. (1983). Stock return seasonalities and the tax-loss selling hypothesis: analysis of the arguments and Australian evidence, Journal of Financial Economics, 12, 105-28.

Cambell J.Y., Lo A.W., MacKinlay A.C. (1997). The Econometrics of Financial Markets, Princeton University Press, Princeton, New Jersey, USA.

Capaul C., Rowley I. \& Sharpe W. (1993). International value and growth stock returns, Financial Analysts Journal, 49, 27-36.

Carhart M.M. (1997). On Persistence in Mutual Fund Performance, Journal of Finance, 52(1), 57-82

Chan L.K.C, Hamao Y. \& Lakonishok J. (1991). Fundamentals and stock returns in Japan, Journal of Finance, 46, 1739-1764. 
Chui A.C.W., Titman S. \& Wei K.C.J. (2000). Individualism and momentum around the world, Journal of Finance, $65,361-392$.

Cochrane J.C. (2005). Asset Pricing, Princeton University Press, Princeton, New Jersey, USA.

Cook T.J. \& Roseff M. (1982). Size Dividend Yield and Co-Skewness Effects on Stock Returns: Some Empirical Tests, Iowa City: University of Iowa, Working Paper Series, 18.

Davis L.J. (1994). The cross-section of realized stock returns: The pre-COMPUSTAT evidence, Journal of Finance, 49, 1579-1593

Dimson E., Marsh P. \& Stuanton M. (2011). Investment style: Size, value and momentum, 'Credit Suisse Global Investment Returns Sourcebook 2011', Credit Suisse Research Institute, Zurich, 4154.

Fama E.F. \& French K.R. (2012). Size, Value, and Momentum in International Stock Returns, Journal of Financial Economics, 105(3), 457-72

Fama E.F. \& French K.R. (2008). Dissecting anomalies, Journal of Finance, 63, 1653-1678.

Fama E.F. \& French K.R. (1992). The cross-section of expected stock returns, Journal of Finance, 47, 427-466.

Fama, E.F. \& French K.R. (1993). Common risk factors in the returns on stocks and bonds, Journal of Financial Economics, 33, 3-56.

Fama, E.F., Fisher L., Jensen M., Roll R. (1969). The adjustment of stock prices to new information, International Economic Review, 10, 1-21.

Garff D. (2013). Multi-Style Global Equity Investing: A Statistical Study on Combining Fundamentals, Momentum, Risk and Valuation for Improved Performance, working paper, available at SSRN: http://ssrn.com/abstract=2367400. Gharghori P., Lee R. \& Veeraraghavan M. (2009). Anomalies and stock returns: Australian evidence, Accounting \& Finance, 49(3), 555-576.

Herrera, M. J. \& Lockwood L.J. (1994). The size effect in the Mexican stock market, Journal of Banking and Finance, $18,621-632$

Heston, L., Rouwenhorst K.G. \& Weessels R. E. (1999). The role of beta and size in the cross-section of european stock returns, European Financial Management, 5, 9 -27.

Horowitz J.L., Loughran T. \& Savin N.E. (2000). The disappearing size effect. Research in Economics, 54(1), 83-100. Lam K. (2002). The relationship between size, book-to-market equity ratio, earnings-price ratio, and return for the Hong Kong stock market, Global Finance Journal, 13(2), 163-179.

Lhabitant F.S. (2004). Hedge Funds: Quantitative Insights, Wiley, New York, USA.

Lhabitant F.S. (2007). Handbook of Hedge Funds, Wiley, New York, USA.

Lintner J. (1965). The valuation of risk assets and the selection of risky investments in stock portfolios and capital budgets, Review of Economics and Statistics, 47, 13-37.

Michou M., Mouselli S. \& Stark A. (2010). Fundamental analysis and the modelling of normal returns in the UK, available at SSRN http://ssrn.com/abstract=1607759.

Mossin J. (1966). Equilibrium in a capital asset market, Econometrica, 34, 768-783. 
Reinganum M.R. (1981). Misspecification of Capital Asset Pricing: Empirical Anomalies based on earning' yield and market values, Journal of Financial Economics, 9(1), 19-46.

Rosenberg B., Reid K. \& Lanstein R. (1985). Persuasive evidence of market inefficiency, Journal of Portfolio Management, 11, 9-17.

Rouwenhorst K.G. (1991). Local returns factors and turnover in emerging stock markets, Journal of Finance, 54, 1439 -1464 .

Sharpe W.F. (1964). Capital asset prices: A theory of market equilibrium under conditions of risk, Journal of Finance, $19,425-442$.

Sharpe W.F. (1966). Mutual fund performance, Journal of Business, 39, 119-138.

Sharpe W.F. (1994). The Sharpe Ratio, Journal of Portfolio Management, 21(1), 49-58.

Stattman D. (1980). Book values and stock returns, The Chicago MBA, A Journal of Selected Papers, 4, 25-45.

Treynor J.L. (1966). How to rate management investment funds, Harvard Business Review, 43, 63-75. 